\title{
Representational task formats and problem solving strategies in kinematics and work
}

\author{
Bashirah Ibrahim and N. Sanjay Rebello \\ Department of Physics, Kansas State University, Manhattan, Kansas 66506, USA
}

(Received 3 November 2011; published 14 June 2012)

\begin{abstract}
Previous studies have reported that students employed different problem solving approaches when presented with the same task structured with different representations. In this study, we explored and compared students' strategies as they attempted tasks from two topical areas, kinematics and work. Our participants were 19 engineering students taking a calculus-based physics course. The tasks were presented in linguistic, graphical, and symbolic forms and requested either a qualitative solution or a value. The analysis was both qualitative and quantitative in nature focusing principally on the characteristics of the strategies employed as well as the underlying reasoning for their applications. A comparison was also made for the same student's approach with the same kind of representation across the two topics. Additionally, the participants' overall strategies across the different tasks, in each topic, were considered. On the whole, we found that the students prefer manipulating equations irrespective of the representational format of the task. They rarely recognized the applicability of a "qualitative" approach to solve the problem although they were aware of the concepts involved. Even when the students included visual representations in their solutions, they seldom used these representations in conjunction with the mathematical part of the problem. Additionally, the students were not consistent in their approach for interpreting and solving problems with the same kind of representation across the two topical areas. The representational format, level of prior knowledge, and familiarity with a topic appeared to influence their strategies, their written responses, and their ability to recognize qualitative ways to attempt a problem. The nature of the solution does not seem to impact the strategies employed to handle the problem.
\end{abstract}

DOI: 10.1103/PhysRevSTPER.8.010126

PACS numbers: 01.40.Fk

\section{INTRODUCTION}

Problem solving may be considered one of the key elements in any scientific discipline. It provides an opportunity for application of scientific knowledge. From a pedagogical perspective, problem solving may also be viewed as a tool for assessing student learning. In the context of physics and other science disciplines, merely solving problems from the end of the chapter in textbooks does not guarantee an understanding of the concepts underlying physics principles. Several physics education researchers have designed instructional approaches to enhance both students' problem solving skills [1] and conceptual understanding [2]. Several physics educators also reformed the structure of physics courses to promote better learning and problem solving [3-6].

Problem solving strategy has been defined differently over the years. Some researchers (e.g., Polya [7] and Bransford and Stein [8]) have described problem solving as a sequence of procedures to be completed by the solver. Others (e.g., Jonassen [9]) have described problem solving as a cognitive activity involving construction of mental representation. In our study, as in most physics education

Published by the American Physical Society under the terms of the Creative Commons Attribution 3.0 License. Further distribution of this work must maintain attribution to the author(s) and the published article's title, journal citation, and DOI. research, problem solving is completion of tasks similar to end-of-chapter problems in most physics textbooks. Most specifically, we focus on students' responses to tasks structured in different representational modes (linguistic, graphical, and symbolic) requiring the generation of either a quantitative or a qualitative solution.

One aspect of problem solving that has gained much interest in the physics education community is the issue of representation. Meltzer [10] defines "representation" as "the widely diverse forms in which physical concepts may be understood and communicated." The use of external representations plays a key role in the learning process. They support students' comprehension of physical principles or concepts by providing an associated "mental image" to these ideas $[11,12]$. Moreover, by generating and handling external representations students construct the cognitive version of the situation or process being considered, thus facilitating their comprehension of the underlying principles [13-16]. Further, the ability to present information in various representational modes, to interpret and unpack information from a given depiction, and to use this information to generate different representations are scientific skills which students need to develop [17]. Studies concerned with representational issues in problem solving have focused on investigating students' handling of graphical and diagrammatic representations [18-20], teaching the use of multiple representations, and exploring its effect on students' problem solving performance [21-25] and 
conceptual understanding [26-29]. Research studies have also explored students' performance with multiple representations compared to single depictions [30-33].

Further studies in physics education have revealed that students have different problem solving performance when presented with the same problem structured in different representational modes [10,34,35]. Similar findings emerged in the context of mathematics where students from an algebra-based class are provided with the same problems posed with either a linguistic or symbolic format requiring quantitative solutions [36,37]. The results of these studies were explained in terms of factors such as students' prior knowledge, their expectations from the course, their instructional environment, familiarity, competency, and level of comprehension with a particular topic as well as with the representation. The key factor which emerged from studies in both the physics and mathematics domains is concerned with the fact that structuring the same concept in different representational modes elicits the application of different problem solution strategies. Moreover, it was found that students who use consistent problem solving strategies across different representations outperform those whose strategies vary with representation [35]. The authors evoke the possibility of experience and degree of understanding of the concepts portrayed by the representation, rather than the superficial features of the representation, cueing students to use different problem solving strategies. Research studies [38,39] have also shown that students employed different procedures for qualitative and quantitative problems. Even when provided with quantitative problems, Walsh et al. [40] found that novice college students used five different approaches when handling the problems. Kohl and Finkelstein [35] propose that students' decision to use a qualitative or quantitative problem solving approach may be prompted by the features inherent or presented in a representation. Conversely, students' perception of a task as being qualitative or quantitative may guide them in how they use the representation.

Thus far, there is a lack of studies in physics education research (PER) probing into the factors leading to the application of different problem solving strategies with respect to representational format. Additionally, previous studies have not explored and compared the approaches used by individual students when attempting tasks from different topical areas presented with the same representational format. The majority of previous work concerned with problem solving strategies with respect to representational format has focused on providing students with the same task (from the same topic) but posed in different representational forms. One of the goals of this study is to investigate the factors leading to the use of different strategies for solving problems with the same representation. We delineate the effect of representation and the topic under consideration for the application of different approaches. We aim at gaining insights into students' problem solving approaches and the underlying reasons for using these strategies when solving problems posed in different representations, requiring either qualitative or quantitative solutions. Moreover, the study aims at highlighting the problem solving strategy employed by the same student across the different tasks. We thus consider and represent individual students' actions (problem solving strategies) as well as their justifications for their actions across the different problems, in the context of kinematics and work, respectively, over the course of four interview sessions. A comparison is then made for any consistencies or differences in the problem solving approaches across the two contexts when dealing with the same representational format. The following research questions are addressed:

(1) What strategies do students use while solving problems with different representational formats requiring qualitative and quantitative solutions?

(2) Are there any differences or similarities in students' strategies when solving problems with the same representational format across different topics?

\section{METHODOLOGY}

\section{A. Participants}

The participants were students enrolled in a first semester calculus-based physics course. The cohort consisted of one female and 18 male students volunteering for the study. The participants were majoring in computer, mechanical, industrial, or chemical engineering, biology, and mathematics. They were concurrently completing Calculus II or III. Among these 19 participants, four of them had not taken physics in high school.

\section{B. Data collection instruments}

A total of 10 tasks were designed. The tasks required either qualitative or quantitative solutions and covered concepts in kinematics (five tasks) and work (five tasks). The tasks were posed in different representational modes (graphical, symbolic, or linguistic) and were nondirective in nature. The students were not presented with any prescribed steps to be followed. They were asked to devise their own procedures for solving the problems. A total of four tasks were presented in graphical form. The students were required to interpret the representation followed by either the formulation of a written response or the generation of a quantitative answer. From each topic, there was only one task posed in linguistic form (as a problem statement) that required the calculation of an unknown quantity. The remaining four tasks, structured in symbolic form, dealt with the generation of either a quantitative or qualitative (linguistic representation) solution. No tasks were presented with a diagrammatic format since one of the aims of the study is also to explore whether the students recognize the importance of visual representations and include them in their problem solution. Moreover, it is 
assumed that posing a problem in diagrammatic form will prompt the students to use a quantitative approach to attempt the problem, thus influencing the strategy used. The tasks are presented in Appendix A.

\section{Administration of instruments}

The tasks were administered either while the students were covering the relevant topic in class or 1 week after they had covered the topic. Data collection occurred during four sessions which spanned 2 months. A minimum of two or a maximum of four students, depending on their availability, were scheduled to individually participate in an interview session per day. Each session consisted of two or three questions which were attempted on an individual basis and in strict sequence. Once a question was completed, it was handed over and the participant was not allowed to view the problem again. The learners were allocated 20-30 minutes to complete the problems, and individual interviews which lasted 15-20 minutes were conducted immediately after completion of the tasks. The four sessions, for each student, were videotaped and the interviews were also audiotaped.

Individual interviews were conducted principally for probing the justifications underlying each student's actions (strategies) when solving the tasks posed in different representational formats. The interview questions were geared towards eliciting the reasons for using particular problem solving strategies, the awareness of alternative methods, and the reasons for not applying these procedures if they were recognized. The students were also questioned about the absence or presence of visual representations in their problem solution. Additionally, the participants were probed about their understanding of certain concepts. These included comprehension of mathematical operations such as integration and differentiation and their connection to the area under a curve and slope of kinematics graphs as well as the awareness of the relationship between the different motion graphs. These questions were designed to provide information about students' familiarity and level of comprehension of the presented concepts and hence act as additional supporting evidence for their preference on using a particular strategy. Finally, the interview questions were designed to aid in dissipating the interviewer's misunderstanding about the use of ambiguous physics terms in the written responses formulated by the student.

\section{Analysis}

The data analysis involved a combination of qualitative and quantitative approach. We were interested in gathering individual student problem solving strategies across the various tasks structured with different representations. Profiles of each participant were thus designed based on the students' actions when attempting the different tasks. The strategies were gathered from both students' written solutions and their responses to the interview questions. The word profile may be understood as a set of descriptors which are put together to represent the students' overall actions across the various tasks [41]. For a particular student, in a given topic, the procedure employed to complete each of the five tasks was considered, summarized, and hence synthesized into a resulting profile. The same process was repeated for each participant in the whole cohort whereby the descriptors were also refined. For problems requesting the formulation of a linguistic representation, we focused on whether the written response was in the form of a description (referring only to apparent, obvious information or surface features of the representation) or an explanation (highlighting derived, additional physics information from the given representation). Consideration was also made for the use of calculus (integration and differentiation) when interpreting the given kinematics equation. When solving for a quantitative solution from a problem statement, we took into account the inclusion of visual representations together with their role in the problem solution or the direct use of equations. For tasks requiring the generation of a value from a symbolic or graphical representation, we emphasized whether the problem was solved using a "qualitative" or quantitative approach, the student's recognition of the "qualitative" approach, and hence its applicability if a quantitative method was preferred. In this study, the term "qualitative" strategy refers to identifying and using the concepts depicted by the graph to solve the problem rather than prioritizing the values presented on the graph and plugging them in equations. It must be noted that the analysis did not attend to the correctness or incorrectness of the problem solution. Coding schemes were developed in order to facilitate comparison of strategies with respect to the solution of the problem being qualitative or quantitative in nature, the representational format of the task, and the topic under consideration. Comparison of problem solving approaches employed by the same student in the two physics topics when handling tasks with the same representational mode was also performed. The codes focused on the same aspects highlighted when constructing the profiles. The profile allocation was repeated independently by another researcher. An inter-reliability rate of $85 \%$ was obtained.

\section{RESULTS}

\section{A. Number of students using a particular problem solving strategy for the different tasks in kinematics}

Table I provides an overview of the number of students using a particular approach when interpreting the symbolic (question 1) and graphical (question 4) representation, respectively, for formulating a qualitative response (linguistic representation).

When interpreting the kinematics equation for position, although all the students formulated an explanation, a higher proportion (15 in 19) of them additionally 
TABLE I. Strategy when formulating a qualitative response for symbolic and graphical representations in kinematics.

\begin{tabular}{lcc}
\hline \hline & \multicolumn{2}{c}{ Representation } \\
Strategy & Symbolic & Graphical \\
\hline Explanation only & 4 & 19 \\
Explanation and calculus & 15 & 0 \\
Description & 0 & 0 \\
Total & 19 & 19 \\
\hline \hline
\end{tabular}

manipulated calculus. For the task structured as an acceleration-time graph, all 19 students in the sample generated an explanation for the physics concepts involved.

The problem solving approaches employed when solving for a quantitative solution from the tasks posed in symbolic (question 3), graphical (question 5), and linguistic (question 2) form, respectively, are shown in Table II.

For the task structured with a symbolic format, all 19 students utilized equations or calculus with the majority (17 in 19) of them not recognizing the applicability of a qualitative approach (sketching the velocity-time graph and determining the area) for attempting the problem. For the task posed in graphical form, a higher proportion (11 in 19) of the students manipulated equations or calculus as the main strategy with only two of them recognizing that the problem can be attempted qualitatively. A total of eight students in the sample used a combination of qualitative and quantitative strategy. When determining a value for the task presented in linguistic form, 10 of the 19 students included a diagram in their problem solution although it was not considered when manipulating the mathematical part of the problem while the remaining nine students directly manipulated equations.

\section{B. Profiles for problem solving strategies on the topic of kinematics}

The profiles for the strategies used by the students across the various kinematics tasks posed with different representations are shown in Table III. Illustrations of a particular student's written solutions together with

TABLE II. Strategy when solving for a quantitative solution from symbolic, graphical, and linguistic representations in kinematics.

\begin{tabular}{|c|c|c|c|}
\hline Strategy & Symbolic & $\begin{array}{c}\text { Representatic } \\
\text { Graphical }\end{array}$ & Linguistic \\
\hline Equations or calculus. Do not recognize qualitative approach & 17 & 9 & $\cdots$ \\
\hline Equations or calculus. Recognize qualitative approach & 2 & 2 & $\cdots$ \\
\hline Equations and qualitative approach & 0 & 8 & $\cdots$ \\
\hline Find area under graph (qualitative approach) & 0 & 0 & $\cdots$ \\
\hline Diagrams dissociated from equations & $\cdots$ & $\cdots$ & 10 \\
\hline Diagrams related to equations & $\cdots$ & $\cdots$ & 0 \\
\hline Equations only & $\cdots$ & $\cdots$ & 9 \\
\hline Total & 19 & 19 & 19 \\
\hline
\end{tabular}

TABLE III. Problem solving strategies for tasks with different representational formats in kinematics.

\begin{tabular}{lll}
\hline $\begin{array}{l}\text { Interpretation of a graph and a } \\
\text { function }\end{array}$ & $\begin{array}{l}\text { Strategy when solving for a value from a } \\
\text { function and a graph }\end{array}$ & $\begin{array}{l}\text { Strategy when solving for a value from a } \\
\text { problem statement }\end{array}$ \\
\hline
\end{tabular}

An explanation highlighting the physics concepts is formulated. Additionally, calculus is applied in a routine manner when presented with a function.

Equations or calculus are used to solve
the problems. Although there may be awareness of the concepts involved in a velocity-time graph, it was not recognized that the problems can be solved qualitatively.

An explanation highlighting the physics concepts is formulated. Additionally, calculus is applied in a routine manner when presented with a function.
Equations or calculus are used to solve problems. Although an expression for acceleration is obtained qualitatively from the given velocity-time graph, the problem is solved using kinematic equations.
Equations are directly used with pattern matching of given and required information. No diagram was included out of habit, because of the extent of information provided and the simplicity of the concept involved.

Diagrams are inclusive in the problem solution with the purpose to better understand and visualize the situation. They are dissociated from the equations.

Either diagrams are inclusive in the problem solution but not related to the mathematical representation or no diagram is explicitly included since the situation was simple and easy to visualize mentally.

Total

$19(100 \%)$
$7(37 \%)$

$4(21 \%)$

$8(42 \%)$ 
interview responses for the two profiles are presented in Appendix B.

A total of 11 of the 19 students formulated an explanation of the physics concepts when interpreting the kinematics equation for position and the motion graph for acceleration. However, when dealing with the position equation, there was a tendency to additionally apply calculus in a mechanical manner. The students used differentiation to obtain an expression for velocity which was further differentiated to determine a value for acceleration. The participants employed a quantitative approach when solving for a value from the tasks posed in symbolic and graphical form, respectively. For the task presented as a velocity equation, on one hand, integration and differentiation were most commonly used to determine a value for position and acceleration, respectively. On the other hand, other equations of motion were applied to solve the problem. When dealing with the motion graphs for position and velocity, the students employed kinematics equations as the principal problem solving approach. During the interview, it was found that a minority (four in 11) of these students were able to articulate that the slope and area under a velocity-time graph yields the acceleration and position, respectively, when presented with the velocity equation problem. In contrast, nine of the 11 students displayed awareness of this particular notion for the problem posed in the form of motion graphs for position and velocity. When solving for a value from a problem statement, seven of the 11 participants directly manipulated equations. A list is made of all the given and required information together with the formulas which can fit maximum information. The reasons provided for not including a diagram range from their routine pattern for solving problems, the extent of information presented in the question, to the simplicity of the concept. In four cases, a diagram was included in the problem solution with the purpose of having a better understanding and visualization of the situation. The visual and mathematical representations were completely dissociated from each other.

The remaining eight students in the sample also provided a written response in the form of an explanation and additionally manipulated calculus for the problem presented with a symbolic format. For the task posed in the form of a velocity equation, a value for work was solved for quantitatively. Either kinematics equations or calculus was employed. During the interview, it was found that most (six in eight) of these students did not recognize the applicability of a qualitative strategy to attempt the problem although they were able to articulate that the slope and area under a velocity-time graph yield the acceleration and position, respectively. In only two cases, the use of the graphical method was recognized but not used since according to the students there is more familiarity with the use of equations which is also simpler. When attempting the problem structured in the form of motion graphs for position and velocity, an expression for acceleration was initially obtained qualitatively from the velocity-time graph but was consequently substituted into a kinematics equation for solving the problem. When probed about their action, the students mentioned familiarity and greater exposure to the notion of acceleration as slope of a velocitytime graph which thus is more readily recognized. Students were uncertain about how to use the graphs for qualitatively solving a problem and referred to their routine problem solving strategy as involving the translation of information into a symbolic form. They also stated that they were more comfortable with manipulating equations and were thinking in terms of which mathematical formulations to use. Finally, when solving for the task presented in the form of a linguistic representation, on one hand, the students included a diagram in the problem solution with the sole purpose of better understanding and visualizing the situation described. It was, however, handled completely in isolation from the equations used. On the other hand, no diagrams were included since the situation was simple and easy to visualize mentally.

\section{Number of students using a particular problem solving strategy for the different tasks on work}

Table IV provides an overview of the number of students using a particular approach when interpreting the symbolic (question 6) and graphical (question 7) representation, respectively, for formulating a linguistic representation.

The majority (16 in 19) of the students generated a description when interpreting the force-position equation compared to only three students formulating an explanation of the physics concepts presented. In contrast, when handling the force-position graph, a higher proportion (11 in 19) of the sample formulated an explanation as opposed to eight students generating a description.

The problem solving approach employed when solving for a quantitative solution from the tasks posed in symbolic (question 8), graphical (question 10), and linguistic (question 9) form, respectively, are shown in Table V.

All 19 students in the sample utilized equations or calculus when solving for a value from the task structured in symbolic form with only three of these students recognizing that the problem can be attempted qualitatively. In

TABLE IV. Strategy when formulating a qualitative response from symbolic and graphical representations in work.

\begin{tabular}{lcc}
\hline \hline & \multicolumn{2}{c}{ Representation } \\
Strategy & Symbolic & Graphical \\
\hline Explanation only & 3 & 11 \\
Explanation and calculus & 0 & 0 \\
Description & 16 & 8 \\
Total & 19 & 19 \\
\hline \hline
\end{tabular}


TABLE V. Strategy when solving for a quantitative solution from symbolic, graphical and linguistic representations in work.

\begin{tabular}{|c|c|c|c|}
\hline Strategy & \multicolumn{3}{|c|}{ Representation } \\
\hline Equations or calculus. Do not recognize qualitative approach & 16 & 9 & $\cdots$ \\
\hline Equations or calculus. Recognize qualitative approach & 3 & 0 & $\ldots$ \\
\hline Equations and qualitative approach & 0 & $\cdots$ & $\cdots$ \\
\hline Find area under graph (qualitative approach) & 0 & 10 & $\cdots$ \\
\hline Diagrams dissociated from equations & $\cdots$ & $\cdots$ & 11 \\
\hline Diagrams related to equations & $\cdots$ & $\cdots$ & 8 \\
\hline Equations only & $\cdots$ & $\cdots$ & 0 \\
\hline Total & 19 & 19 & 19 \\
\hline
\end{tabular}

contrast, when dealing with the force-position graph, 10 of the 19 students solved the problem by determining the area under the graph to obtain the work done while the remaining nine students used a quantitative approach with no recognition of the applicability of a qualitative strategy. Finally, for the task structured as a problem statement, although all the students included a visual representation (sketch and/or free-body diagram), in only eight cases, the diagrams were used in conjunction with the mathematical part of the problem.

\section{Profiles for problem solving strategies in the topic of work}

Table VI provides an overview of the strategies used by the students when attempting the various tasks in the context of work structured in linguistic, symbolic, and graphical forms, respectively. Examples of a particular student's problem solving strategy across the five tasks together with interview responses are provided in Appendix C.

The majority of the cohort (15 in 19,79\%) formulated a description when interpreting the symbolic representation relating force and position. For the graphical version, if the students (five in 15) generated an explanation, the concept was highlighted in a rote manner, mentioning that the area under the force-position graph yields the work done. The description focused on apparent information as well as on surface features of the representation. For the force equation, the students referred to the magnitude of the applied force at different positions and in rare cases also mentioned its direction. They identified the variables which compose the equation and finally stated its corresponding parabolic shape since the function is a quadratic one. The description for the force-position graph includes highlighting the relationship between these two variables by either referring to the magnitude of the applied force at specific positions or making a brief statement about the general trend observed. When solving for a quantitative solution from the task posed in symbolic form, all the students employed a quantitative approach. They determined a value for work by using the equation for constant force with no recognition or awareness of a qualitative method for handling the problem. For the task presented in the form of a pressure-volume graph, two strategies were applied to solve for work. On one hand, six of the 15 students employed a qualitative approach by finding the area under the graph in a rote and mechanical manner. According to these students, when provided with any graphical representation, determining the area is one of the routine procedures

TABLE VI. Profiles for problem solving strategies with different representational task formats in the context of work.

\begin{tabular}{|c|c|c|c|c|}
\hline $\begin{array}{l}\text { Interpretation of a graph } \\
\text { or a function }\end{array}$ & $\begin{array}{l}\text { Strategy when solving } \\
\text { for a value from a } \\
\text { function }\end{array}$ & $\begin{array}{l}\text { Strategy when solving } \\
\text { for a value from a graph }\end{array}$ & $\begin{array}{l}\text { Strategy when solving for a } \\
\text { value from a problem statement }\end{array}$ & Total $(\%)$ \\
\hline $\begin{array}{l}\text { Formulate a description in- } \\
\text { stead of an explanation. If } \\
\text { concepts are highlighted for } \\
\text { the graph, it is done in a rote } \\
\text { manner. }\end{array}$ & $\begin{array}{l}\text { Equation is used with no } \\
\text { recognition of qualitative } \\
\text { strategy. }\end{array}$ & $\begin{array}{l}\text { On one hand, a qualitative } \\
\text { approach is used in a rote } \\
\text { manner. On the other hand, } \\
\text { a formula, which may have } \\
\text { been generated from the } \\
\text { graph, is used. }\end{array}$ & $\begin{array}{l}\text { Sketch is drawn to visualize and } \\
\text { understand the situation. A free- } \\
\text { body diagram may be included. } \\
\text { Visual representations are not re- } \\
\text { lated to the equations used. }\end{array}$ & $15(79 \%)$ \\
\hline \multirow[t]{2}{*}{$\begin{array}{l}\text { Formulate a description for } \\
\text { the function but generate an } \\
\text { explanation for the graph. }\end{array}$} & $\begin{array}{l}\text { Calculus is used although } \\
\text { there is awareness of } \\
\text { qualitative strategies. }\end{array}$ & $\begin{array}{l}\text { Problem is solved qualita- } \\
\text { tively. The graph is used to } \\
\text { reason about the concept. }\end{array}$ & $\begin{array}{l}\text { Sketch is drawn to visualize and } \\
\text { understand the situation. A free- } \\
\text { body diagram is included. The vis- } \\
\text { ual representations are related to } \\
\text { the equations used. }\end{array}$ & $4(21 \%)$ \\
\hline & & & Total & $19(100 \%)$ \\
\hline
\end{tabular}


which can be used to attempt the problem. On the other hand, the remaining nine students used a quantitative problem solving strategy. They either applied the memorized equation for work done by constant force or derived a formula relating the product of pressure and volume by manipulating the units of these variables to obtain that of work which is Nm or Joules. They consequently solved the problem by finding the difference of the product of these two variables at the specified points. Finally, when handling the task presented in linguistic form, eight of the 15 students drew a sketch for the situation described as well as a free-body diagram. However, in only four cases, the visual representations were considered when manipulating the mathematical part of the task. The remaining seven students provided only either a free-body diagram or a sketch, which were ignored when dealing with the symbolic representations.

A total of four students in the cohort generated a description when interpreting the force function mentioning either the magnitude of the applied force at different positions or the parabolic shape of its corresponding graph. The same students formulated an explanation for the forceposition graph. However, they either interpreted the graph as a kinematics one (thus highlighting irrelevant physics concepts) or referred solely to the idea that the area under the curve yields work. For the task structured as a function relating force and position requiring a value, the students employed calculus, which is the equation for work done by nonconstant force although there is awareness of the qualitative strategy. The reason provided for using this particular method is that the integral is equivalent to the area under the graph and hence it is simpler to manipulate calculus. When solving for a quantitative solution from the pressure-volume graph, all the participants employed a qualitative approach by finding the area under the graph. Finally, when working out a quantitative solution from the problem statement, they included both a sketch depicting the situation described and a free-body diagram in the problem solution. These visual representations were then related to the mathematical formulations used.

\section{E. Effect of representation on problem solving strategy}

When interpreting a symbolic or graphical representation, from either kinematics or work, the representation at hand may have had an influence on the students' actions in their generation of a written response. From Table I, in kinematics, based on the proportion of students generating an explanation only and an explanation together with manipulation of calculus, it can be said that the presence of an equation may have prompted the students to additionally perform differentiation in a rote and mechanical manner compared to when the task is structured in graphical form. Moreover, from Table IV, for the topic on work, the fact that the task is presented in graphical form may have made it easier for the students to recognize and hence derive the physics concepts involved in the task which was otherwise difficult when presented in symbolic form.

The effect of representational format on problem solving strategy was also observed when solving for a value from tasks posed in symbolic, graphical, and linguistic forms (Tables II and V). The whole sample, in either topic, manipulated equations. Structuring a task in graphical form also prompted the students to use a qualitative problem solving approach. In kinematics, although most students (11 in 19, Table II) manipulated equations or calculus, a proportion of the sample (eight in 19) first handled the problem qualitatively and then used equations. These students employed a combination of both qualitative and quantitative approach. For the topic on work, even if a negligible difference (Table V) was observed in the number of students using a qualitative or quantitative approach, the presence of a graphical representation may have prompted the students to solve the problem by taking the area under the force-position graph. All 19 students included a diagram when handling the task structured in linguistic form for the topic on work. In kinematics, a small difference (Table II) was noted in the number of students including a diagram and those manipulating equations only. The latter category of students, during interviews, referred to the simplicity of the problem and hence being easily visualized mentally and resulting in the noninclusion of a diagram.

\section{F. Effect of quantitative and qualitative (linguistic representation) solution on problem solving strategy}

The approaches used when attempting tasks structured with a symbolic representation requiring qualitative and quantitative solutions (questions 1, 3, 6, and 8) from kinematics and work are shown in Table VII.

In kinematics, a high proportion of students manipulated equations or calculus irrespective of whether the task with symbolic format requires the generation of a qualitative ( 15 in 19) or a quantitative (all 19 students) solution. For the tasks concerned with work, all the students in the sample used a quantitative approach when solving for a value. Moreover, when interpreting the force-position equation, more students (16 in 19) formulated a description emphasizing the surface features of the representation rather than focusing on the derivation of physics information. Hence, it can be said that the solution of the task, qualitative or quantitative, does not influence the students' problem solving strategy when the problem is posed in symbolic form.

Table VIII provides an overview of the strategy used when attempting tasks, from the two topics, structured with a graphical format requiring a qualitative or a quantitative answer (questions 4, 5, 7, and 10).

In kinematics, when interpreting the motion graph, all 19 students formulated an explanation, and when solving for a value, a higher proportion of students (11 in 19) used a purely quantitative approach. However, for the tasks on work, although more students (11 in 19) generated an 
TABLE VII. Comparison of strategies when handling tasks, from kinematics and work, posed in symbolic form.

\begin{tabular}{|c|c|c|c|c|}
\hline \multirow[b]{2}{*}{ Strategy } & \multicolumn{2}{|c|}{ Kinematics } & \multicolumn{2}{|c|}{ Work } \\
\hline & Qualitative solution & Quantitative solution & Qualitative solution & Quantitative solution \\
\hline Explanation only & 4 & $\cdots$ & 3 & $\cdots$ \\
\hline Explanation and calculus & 15 & $\cdots$ & 0 & . . \\
\hline Description & 0 & $\cdots$ & 16 & .. \\
\hline $\begin{array}{l}\text { Equations or calculus. Do not recognize } \\
\text { qualitative approach }\end{array}$ & $\ldots$ & 17 & $\ldots$ & 16 \\
\hline $\begin{array}{l}\text { Equations or calculus. Recognize } \\
\text { qualitative approach }\end{array}$ & $\cdots$ & 2 & $\cdots$ & 3 \\
\hline Total & 19 & 19 & 19 & 19 \\
\hline
\end{tabular}

TABLE VIII. Comparison of strategies when handling tasks, from kinematics and work, posed in graphical form.

\begin{tabular}{|c|c|c|c|c|}
\hline \multirow[b]{2}{*}{ Strategy } & \multicolumn{2}{|c|}{ Kinematics } & \multicolumn{2}{|c|}{ Work } \\
\hline & Qualitative solution & Quantitative solution & Qualitative solution & Quantitative solution \\
\hline Explanation & 19 & $\ldots$ & 11 & $\ldots$ \\
\hline Description & 0 & $\ldots$ & 8 & $\cdots$ \\
\hline Equations and qualitative approach & $\cdots$ & 8 & $\cdots$ & 0 \\
\hline $\begin{array}{l}\text { Equations or calculus. Do not recognize } \\
\text { qualitative approach }\end{array}$ & $\cdots$ & 9 & $\cdots$ & 9 \\
\hline $\begin{array}{l}\text { Equations or calculus. Recognize } \\
\text { qualitative approach }\end{array}$ & $\cdots$ & 2 & $\cdots$ & 0 \\
\hline Find area under graph (qualitative approach) & $\cdots$ & 0 & & 10 \\
\hline Total & 19 & 19 & 19 & 19 \\
\hline
\end{tabular}

explanation, a negligible difference was observed in the number of students using a qualitative or quantitative approach when solving for a value from the force-position graph. Consequently, it cannot be ascertained that the solution being qualitative or quantitative in nature has an effect on the students' problem solving strategy although a trend is observed when handling the kinematics tasks only.

\section{G. Effect of topic on problem solving strategy}

The problem solving approaches employed when generating a qualitative answer across the topics of kinematics and work (questions 1, 4, 6 and 7) are shown in Table IX.

For the tasks with a symbolic format requiring a qualitative solution, the data indicate that in kinematics all 19 students formulated an explanation of the physics depicted by the position equation, while in the topic of work, a high proportion of students (16 in 19) formulated a description

TABLE IX. Comparison of strategies when handling tasks across the two topics requiring a qualitative solution.

\begin{tabular}{lcccc}
\hline \hline & \multicolumn{2}{c}{ Symbolic } & \multicolumn{2}{c}{ Graphical } \\
Strategy & Kinematics & Work & Kinematics & Work \\
\hline Explanation only & 4 & 3 & 19 & 11 \\
$\begin{array}{l}\text { Explanation and } \\
\text { calculus }\end{array}$ & 15 & 0 & 0 & 0 \\
$\begin{array}{l}\text { Description } \\
\text { Total }\end{array}$ & 0 & 16 & 0 & 8 \\
\hline \hline
\end{tabular}

focusing on apparent information and surface features of the representation. When interpreting the acceleration-time graph, the whole sample provided an explanation. A higher proportion of students (11 in 19) generated an explanation, often in a rote manner, for the force-position graph. Hence, it can be said that the topic under consideration has an influence on whether the students formulate a description or an explanation.

Table $\mathrm{X}$ presents an overview of the approaches used when determining a quantitative solution from the topics of kinematics and work (questions 2, 3, 5, 8, 9, and 10).

Irrespective of whether the task is from kinematics or work, when presented with a symbolic format, all 19 students employed a quantitative approach. For the task posed in graphical form, in kinematics, more (11 in 19) students used a quantitative approach, while in the topic on work, a negligible difference was noted in the number of students using a qualitative (10 in 19) or a quantitative (9 in 19) problem solving strategy. When dealing with the kinematics tasks structured in linguistic form, a negligible difference was observed in the number of students manipulating equations only (9 in 19) and including a diagram (10 in 19). However, for the topic on work, the whole sample included visual representations (sketch and/or free-body diagram) in their problem solution. Consequently, it can be concluded that the topic under consideration does seem to have an effect on students' problem solving approach although the data indicate that 
TABLE X. Strategy when handling tasks across the two topics requiring a quantitative solution.

\begin{tabular}{lrrrrrr}
\hline \hline \multirow{2}{*}{ Strategy } & \multicolumn{2}{c}{ Symbolic } & \multicolumn{2}{c}{ Graphical } & \multicolumn{2}{c}{ Linguistic } \\
Einematics & Work & Kinematics & Work & Kinematics & Work \\
\hline Equations or calculus. Do not recognize qualitative approach & 17 & 16 & 9 & 9 & $\ldots$ & $\ldots$ \\
Equations or calculus. Recognize qualitative approach & 2 & 3 & 2 & 0 & $\ldots$ & $\ldots$ \\
Find area under graph (qualitative approach) & $\ldots$ & $\ldots$ & 0 & 10 & $\ldots$ & $\ldots$ \\
Equations and qualitative approach & $\ldots$ & $\ldots$ & 8 & 0 & $\ldots$ & $\ldots$ \\
Diagrams dissociated from equations & $\ldots$ & $\ldots$ & $\ldots$ & $\ldots$ & 10 & 11 \\
Diagrams related to equations & $\ldots$ & $\ldots$ & $\ldots$ & $\ldots$ & 0 & 8 \\
Equations only & $\ldots$ & $\ldots$ & $\ldots$ & $\ldots$ & 9 & 0 \\
Total & 19 & 19 & 19 & 19 & 19 & 19 \\
\hline \hline
\end{tabular}

they all used a quantitative approach when dealing with the tasks in symbolic format.

\section{H. Comparing the same student's problem solving strategies with the same representational format across the two topics}

A comparison is made for the problem solving strategy used by the same student when handling tasks with the same representational format across the two topics. The results for the strategies used by the same student when interpreting a kinematics equation for position (question 1) and acceleration-time graph (question 4) as well as a function (question 6) and graphical representation (question 7) relating force and position are presented in Table XI. The headings "S-L" and "G-L" represent translation from symbolic and graphical representation, respectively, to linguistic representation, which is a qualitative solution.

The data revealed that for the problems structured in symbolic form, most (12 in 19) students formulated an explanation when interpreting the kinematics equation but generated a description for the force function. A minority of the participants consistently provided an explanation (two in 19) or a description (five in 19) across the two topics.

For the tasks presented in graphical form, the inverse was observed with more students (11 in 19) formulating an explanation in both topics. However, it should be pointed out that the written response highlighting the notion of area under a force-position graph yielding the work done was generated mainly in a rote manner. The remaining students (eight in 19) provided a description when interpreting the

TABLE XI. Strategy used by the same student when interpreting symbolic and graphical representation across the two contexts.

\begin{tabular}{lrr}
\hline \hline & \multicolumn{2}{c}{ Task } \\
Strategy used & S-L & G-L \\
\hline Consistent generation of an explanation. & 2 & 11 \\
Consistent generation of a description. & 5 & 0 \\
Generation of an explanation in kinematics & 12 & 8 \\
but formulation of a description in work. & & \\
\hline \hline
\end{tabular}

force-position graph but formulated a linguistic representation focusing on derived information from the motion graph for acceleration.

Table XII provides an overview of the different ways in which the same student handled the problems presented in linguistic (questions 2 and 9), symbolic (questions 3 and 8 ,) and graphical (questions 5 and 10) forms, requiring a numerical solution, across the two topics. The headings "L-N," "S-N," and "G-N" represent translation from linguistic, symbolic, and graphical representation, respectively, to numerical form.

When solving for a value from the problem statements, more than half of the sample (13 in 19) included visual representations in their problem solution regardless of the context. A total of six of the 19 students used different problem solving strategies when dealing with the topic on kinematics and work. They directly manipulated equations when dealing with the kinematics tasks but included visual representations for the problems concerned with work. Most of these students (11 in 19) consistently dissociated the visual depictions (sketch for the situation and/or freebody diagrams) from the mathematical part of the problem. A total of five students used their generated diagrams in conjunction with the mathematical formulations for the topic on work only. When comparing the two topics, a negligible difference was observed in how students used the visual depictions in connection to the mathematical formulations. The visual representations were considered independently from the equations by 10 of 19 students when handling the kinematics tasks and 11 of the 19 participants for the problems on work. Moreover, it was observed that visual representations were included by all 19 students when solving problems concerned with work. This finding may be attributed to how students were taught to attempt problems in this particular context. They were explicitly exposed to the problem solving strategy of including a sketch followed by a free-body diagram before manipulating the equations which were consequently used to solve for a value.

For the tasks posed in symbolic form requesting the generation of a value, all 19 students consistently apply a quantitative approach as the main problem solving 
TABLE XII. Strategy used by the same student when generating mathematical formulation from task posed in linguistic, symbolic, and graphical representations across the two contexts.

\begin{tabular}{|c|c|c|c|}
\hline Strategy used & L-N & $\begin{array}{l}\text { Task } \\
\text { S-N }\end{array}$ & G-N \\
\hline $\begin{array}{l}\text { Direct use of equations in kinematics but inclusion of visual representations which are not } \\
\text { related to the equations used in the context of work. }\end{array}$ & 6 & $\cdots$ & $\cdots$ \\
\hline \multicolumn{4}{|l|}{ Consistent inclusion of visual representations which are } \\
\hline - related to the equations used & 3 & $\cdots$ & $\cdots$ \\
\hline - not related to the equations used & 5 & $\cdots$ & $\cdots$ \\
\hline - related to the equations used only in the context of work & 5 & $\cdots$ & $\cdots$ \\
\hline \multicolumn{4}{|l|}{ Consistent use of equations } \\
\hline - with no recognition of qualitative strategies & $\cdots$ & 15 & 6 \\
\hline - although there is awareness of qualitative strategies & $\cdots$ & 1 & $\cdots$ \\
\hline - although they recognize qualitative strategy in either only kinematics or only work & $\cdots$ & 3 & $\cdots$ \\
\hline \multicolumn{4}{|l|}{$\begin{array}{l}\text { Appeal to qualitative reasoning in kinematics although the problem is solved using equations } \\
\text { and in the context of work }\end{array}$} \\
\hline - qualitative approach is used & $\cdots$ & $\cdots$ & 5 \\
\hline - equations are used & $\cdots$ & $\cdots$ & 3 \\
\hline $\begin{array}{l}\text { Use of equations in kinematics with no recognition of qualitative strategy and in the context of } \\
\text { work, problem is solved qualitatively in a rote manner }\end{array}$ & $\cdots$ & $\cdots$ & 5 \\
\hline
\end{tabular}

strategy. A total of 15 of them did not recognize that a qualitative approach, plotting the graph for the given function and finding the area or slope under the graph, can be applied for solving the problems. The remaining four students preferred to manipulate equations (in both or only one topic) although they were aware that the problem can be solved qualitatively. When dealing with the problems presented in the form of graphical representations six of the 19 students consistently used equations across both topics, with no recognition of qualitative strategies, to solve the problem. A total of five students employed different problem solving strategies across the two topics. They used equations to solve the kinematics tasks but applied the area under the force-position graph in a rote manner to find a value for work. It is assumed that the particular procedure was applied in the topic on work, as by the end of the data collection sessions, the students were accustomed to the notion that when provided with a graph, either the area or the slope can be worked out. The remaining eight students appealed to qualitative reasoning in kinematics but solved the problem using equations. However, when handling tasks on work, five of these students applied a qualitative approach while the remaining three students made use of symbolic representations.

\section{DISCUSSION AND CONCLUSION}

Previous studies have explored students' problem solving performance as well as strategies when provided with the same task presented in different representational formats. In contrast, the current work highlights the problem solving approaches employed by the same student across tasks presented in linguistic, graphical, and symbolic forms requiring qualitative (written response) or quantitative solutions. However, the tasks do not present the same concept structured in different representations. The students were instead provided with tasks requiring a variety of basic content knowledge in kinematics and work, which can be solved using different strategies. This research highlighted and compared the problem solving approaches employed across the two topics when dealing with tasks asking for qualitative or quantitative solutions. Furthermore, the factors leading to the application of particular strategies for these various tasks were identified. Specifically, the effect of representational mode, the solution of the problem being qualitative or quantitative in nature, and the topic under consideration on the students' approaches to problem solving were investigated.

We also examined students' problem solving approaches by considering the data with regard to the topic. In kinematics it was revealed that irrespective of the representational mode of tasks requesting a value as solution, the students prioritized the manipulation of symbolic representations even if they were aware of the concepts involved in terms of the relationship between the motion graphs for position, velocity, and acceleration. When interpreting the kinematics equation for position or the acceleration-time graph, they formulated an explanation of the physics concepts but additionally manipulated calculus in a mechanical manner for the task with a symbolic format. However, in the topic of work, it was observed that even though the students focused on the application of a quantitative problem solving strategy, they tended to refer to both approaches principally for the task structured in the form of a pressure-volume graph. A negligible difference was noted in the number of students applying a qualitative (10 in 19) and a quantitative (nine in 19) approach to solve for the work done from this particular task. However, the 
qualitative approach was essentially used in a rote and mechanical manner. When interpreting the graphical and symbolic representations relating force and position, unlike the kinematics topic, the students formulated a description focusing on the apparent information and surface features of the representation. Finally, it was found that, in both topics, a large proportion of the students included a visual representation in their problem solutions with the main purpose of better visualizing and understanding the situation described.

The actions of the same student when dealing with the same representational format across the two topics were compared. The purpose of this analysis is to identify the factors leading to the generation of an explanation or a description. It also aims at distinguishing between as well as delineating the effect of the representation and the topic leading to the application of particular problem solving approaches. When interpreting the symbolic representations, more students were found to consistently provide an explanation for the position equation and at the same time formulate a description for the force-position function. Moreover, a higher proportion of students were noted to consistently formulate an explanation when interpreting the acceleration-time graph as well as the force-position graph. However, in the topic of work, the graph was interpreted as a kinematics one hence generating irrelevant physics information concerned with acceleration and velocity.

Based on the results of this study, it can be argued that the category of the linguistic representation generated is mainly tied to the effect of the students' level of understanding and experience with the topic under consideration. It is assumed that their familiarity and experience in kinematics may have prompted the derivation of physics information presented by the position equation. It may have resulted in deeper level interpretation of the representation, highlighting the underlying physics ideas. In contrast, the students' poor familiarity and limited comprehension of the topic on work may have led to their superficial interpretation of the symbolic representation focusing principally on apparent information. This particular outcome can be compared to the results from the study by Chi et al. [42] in the physics domain as well as Kozma and Russell [43] in the chemistry context where novices' and experts' handling of various representations were compared. It was revealed that novice students who usually have low prior knowledge concentrate on apparent and surface features or information as criteria for categorizing representations. In contrast, experts with greater extent of previous knowledge and understanding emphasize the underlying ideas portrayed by the representation or the task under consideration. However, Kohl and Finkelstein [44] highlighted that no difference was observed in their study on how novices and experts deal with different representations. This particular outcome was attributed to the instructional environment which makes extensive use of different representations during either discourse or problem solving. It should be pointed out that the students in our sample were principally exposed to the traditional method of teaching which did not emphasize the use of multiple representations.

The effect of representational mode on problem solving approach, such as the application of only equations or inclusion of visual representations, was observed for the tasks structured in linguistic form. The data revealed that a minority of the students employed a different approach according to the topic under consideration. A higher proportion (68\%, Table XII) of the students was found to consistently include a visual representation before manipulating the equations irrespective of the topic. This particular outcome may be attributed to the representational task format being linguistic in nature, thus triggering the generation of a diagrammatic representation in the problem solution. As was noted during interviews, the main reason provided for including a diagram is to have a better understanding and visualization of the situation described. It can be argued that the effect of class norms, in terms of how students were taught to solve problems, is also a possibility mainly for the topic on work where it is common to include a sketch followed by a free-body diagram before manipulating the equations. However, no difference was observed in how students used their visual representations in conjunction with the symbolic representations across the two topics. The visual representation, in principal, was not considered when manipulating the mathematical part of the problem. Consequently, it can be stated that the representational mode of the task has a great influence on the students' inclusion of diagram in their problem solution.

For the tasks structured in the form of an equation, irrespective of the topics, it was found that all the students consistently applied a quantitative approach when solving for a value. Further, the majority (89\%) of these students did not recognize, in both topics, the applicability of a qualitative approach for attempting the tasks. The presence of a symbolic representation may have limited the students' thinking beyond the application of a quantitative approach, not recognizing that the problem can be attempted qualitatively. Detailed analysis indicates that in kinematics, additionally, more than half of these students are aware of the relationship between position, velocity, and acceleration, stating that the slope and area under the velocity-time graph yield the acceleration and position, respectively. However, for the topic on work, a negligible one student exhibits awareness and recognition for the application of a qualitative approach for attempting the problem. The majority of the students concentrate only on the use of an equation for work done by constant force. Hence, it can be concluded that for kinematics, where the students have better comprehension and experience, the 
symbolic representation used to structure the task may have influenced the students to employ a quantitative problem solving approach and not recognize the applicability of a qualitative strategy. The application of this particular procedure may also be due to the students' perception that the question is quantitative in nature, asking for a value as highlighted by Sabella [39], which consequently influences how they deal with the symbolic representation [35]. Our data are limited in the fact that we did not interview students specifically on this issue. Evidence which can be provided to support the claim that the students in our study may view a problem as being quantitative in nature when presented with a task structured in symbolic form is that, in addition to formulating an explanation, they manipulated calculus in a mechanical manner when provided with the position equation to be interpreted. In contrast, for the topic concerned with work, the application of equations to solve the problem may be associated with the students' superficial content knowledge and poor conceptual understanding rather than the representational format of the task. Moreover, from Tables VII and VIII, the analysis indicates that the solution of the task being qualitative or quantitative in nature does not seem to influence the problem solving strategy used.

When the tasks are structured in graphical form, it was found that a minority (32\%, Table XII) of the students consistently apply a quantitative problem solving strategy across the two topics. It was noted that most commonly, different strategies were used when attempting the problems from the two topics. On one hand, in kinematics, a combination of qualitative and quantitative approaches was used while the same student, for the topic on work, applied either a qualitative strategy in a rote manner or used equations. On the other hand, equations were applied as the main problem solving strategy when dealing with the kinematics task but a qualitative approach was used in a rote manner for the topic on work. Consequently, it can be said that both the representation of the task and the comprehension of the topic may have influenced the strategy employed for attempting the tasks. The fact that the students are presented with motion graphs for position and velocity may have led them to generate an expression for acceleration qualitatively from the graph. During interviews, the students mentioned greater familiarity and exposure to the notion of acceleration being the slope under the velocity-time graph and hence it is more readily recognizable. They finally made use of kinematics equations to solve the problem since there was less familiarity in terms of how to use the graphs to solve the problem and exposure to the idea of area under velocity-time graph yielding position. Additional evidence for how the graph as well as comprehension level of a topic lead to the application of qualitative approach is for the topic on work. Since the students have a poor comprehension of the content knowledge and are presented with a graphical representation, the latter prompted them to work out the area under the pressure-volume graph to find the work done. As the students stated during interviews, when presented with a graph, the routine strategies which can be used to solve a problem involve the application of either slope or area under the graph.

To summarize, the study further provides evidence of the influence of representation and students' level of understanding as well as prior knowledge of a topic on problem solving strategy including the characteristics of the linguistic representation (qualitative solution) formulated. It presents tasks structured with the same representational format across two topics and explores individual students' actions across the different tasks. Students with low existing knowledge or understanding of a topic tend to generate a description compared to those with higher prior knowledge and comprehension who provide an explanation. The effect of representation together with experience with a particular topic was also observed. On one hand, students with little prior knowledge used a qualitative approach for problem solving in a rote and routine manner when presented with a graphical representation. On the other hand, they start with a qualitative approach and then revert to the use of equations to solve for a value when they are unsure and lack knowledge on how to use the graphs to attempt the problem. Another case which includes the influence of both representation and familiarity with a context is when presented with the tasks posed in symbolic form. The students are very familiar with kinematics and yet did not recognize the applicability of a qualitative approach when presented with the equation for velocity. On the contrary, the students' lack of knowledge for the topic on work principally results in their nonawareness as well as nonrecognition of qualitative strategies, thus leading them to use a quantitative approach. Only the effect of the representational format was observed when the tasks were presented in linguistic form which results in the students generating visual representations before manipulating the equations. However, the visual and mathematical representations were handled in the same way in both contexts.

Our data are limited as it is not possible to identify whether the prioritization for a quantitative problem solving approach is also due to the students' view that the problem is quantitative in nature which therefore influences how they deal with the given representation or if it has to do with their perception about specific representation. Another limitation of the study is that we cannot pronounce much about the effect of the class norms on problem solving procedure as the data are restricted.

\section{IMPLICATIONS FOR INSTRUCTION}

If we want to exploit the benefits of problem solving as a tool in students' learning process for improving comprehension, studies into their problem solving approaches, especially when presented with different representational 
formats, are crucial. It is well known that the application of quantitative strategy (manipulation of equations for attempting problems) does not imply comprehension of concepts presented in the tasks as well as the underlying physics principles of the equations used. According to the Johnson-Laird cognitive framework of sense making [45], it is argued that comprehension occurs with the construction of a mental model which is a key element in the learning process $[46,47]$. However, although the application of external representations promotes the construction of a mental model, the strategies used by the students when attempting tasks with different representational formats play a crucial role. The study by Greca and Moreira [48] characterized students with a mental model as focusing on comprehension and identifying physics ideas, using a qualitative approach for problem solving and also including visual representations which are used in conjunction with the equations. To promote the application of these problem solving approaches, students should be explicitly taught and provided with opportunities to apply these various ways in which problems posed with particular representations can be handled. Emphasis should be placed on the use of qualitative problem solving approaches. The central role of visual representations for qualitative reasoning as well as for generating quantitative solutions should be highlighted. Consequently, the possibility of students constructing mental models during problem solving can be promoted, thus ensuring comprehension of concepts. Moreover, the students' familiarity and ability in dealing with the different kinds of representations in terms of decoding, interpreting, and deriving information from a particular representation, and translating information across different representational modes can be enhanced. These are some of the scientific skills advocated by Etkina et al. [17] which need to be developed.

\section{ACKNOWLEDGMENTS}

This work is supported in part by the U.S. National Science Foundation under Grant No. 0816207.

\section{APPENDIX A}

Question 1: Kinematics-Qualitative-Symbolic

The equation of motion for an object moving along a straight horizontal path is given by

$$
x(t)=30+5 t+2 t^{2}
$$

Write down, in words, everything you can say about the motion of the object.

\section{Question 2: Kinematics-Quantitative-Linguistic}

You are driving at a speed of $60 \mathrm{~m} \mathrm{~s}^{-1}$ when suddenly you see a van $60 \mathrm{~m}$ directly ahead of you also travelling in the same direction at a constant speed of $40 \mathrm{~m} \mathrm{~s}^{-1}$. You

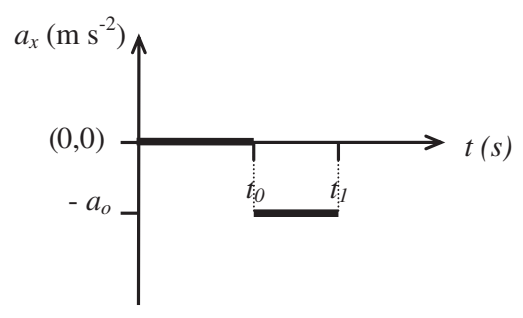

FIG. 1. Kinematic task with graphical format requesting qualitative solution.

immediately apply the brakes and your car starts slowing down at $0.8 \mathrm{~m} \mathrm{~s}^{-2}$. Determine whether a collision will take place.

\section{Question 3: Kinematics-Quantitative-Symbolic}

The equation of motion for an object moving along a straight horizontal path is found to be

$$
v_{x}(t)=3+2 t
$$

If the object was in motion for $5 \mathrm{~s}$, what is the distance travelled and acceleration during this time?

\section{Question 4: Kinematics-Qualitative-Graphical}

The acceleration-time graph for an object moving along a straight horizontal path is shown in Fig. 1.

Write down, in words, everything you can say about the motion of the object

\section{Question 5: Kinematics-Quantitative-Graphical}

The motion of a truck along a straight horizontal path is shown by the graphs below. Determine the time taken and acceleration of the truck to complete the whole journey (see Fig. 2).

\section{Question 6: Work-Qualitative-Symbolic}

Write down everything you can say from the force equation $\overrightarrow{\mathbf{F}}(x)=\left(-4+x^{2}\right) \hat{\mathbf{i}} \mathrm{N}$ applied to move the box from an initial position of $0 \mathrm{~m}$ to final position of $4 \mathrm{~m}$.
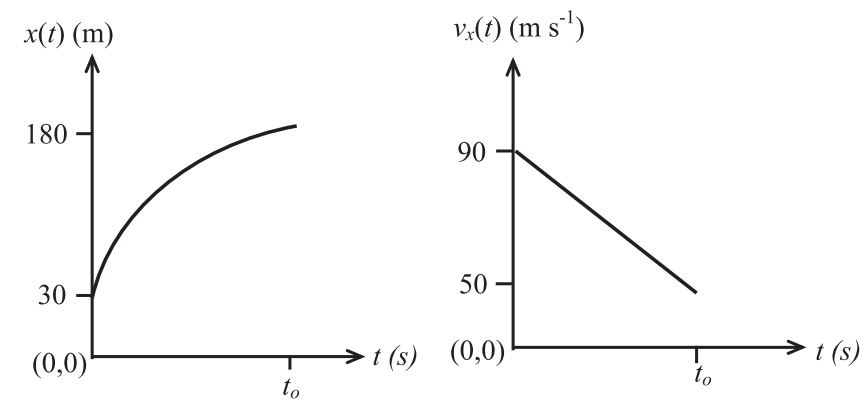

FIG. 2. Kinematic task with graphical format requesting quantitative solutions. 


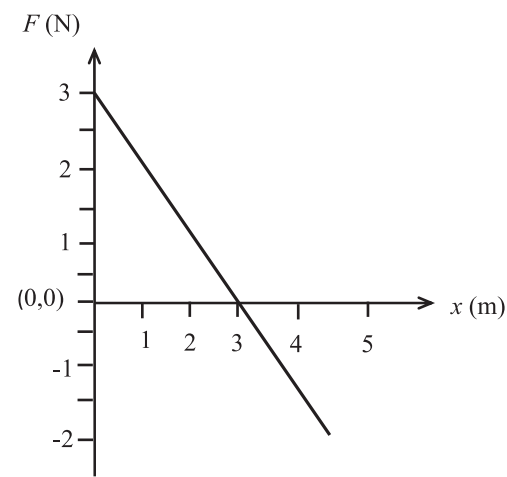

FIG. 3. Force-position graph requesting qualitative solution.

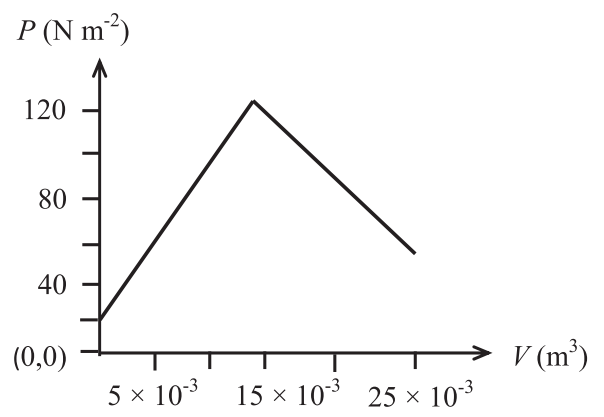

FIG. 4. Pressure-volume graph requesting a quantitative solution.

\section{Question 7: Work-Qualitative-Graphical}

The relationship for the force applied and distance moved by an object from initial position $0 \mathrm{~m}$ to final position $5 \mathrm{~m}$ is shown in Fig. 3.

Write down everything you can say from the graph when the box is moved from an initial position of $0 \mathrm{~m}$ to final position of $5 \mathrm{~m}$.

\section{Question 8: Work-Quantitative-Symbolic}

The force applied in moving a $5 \mathrm{~kg}$ box on a frictionless horizontal surface is given by

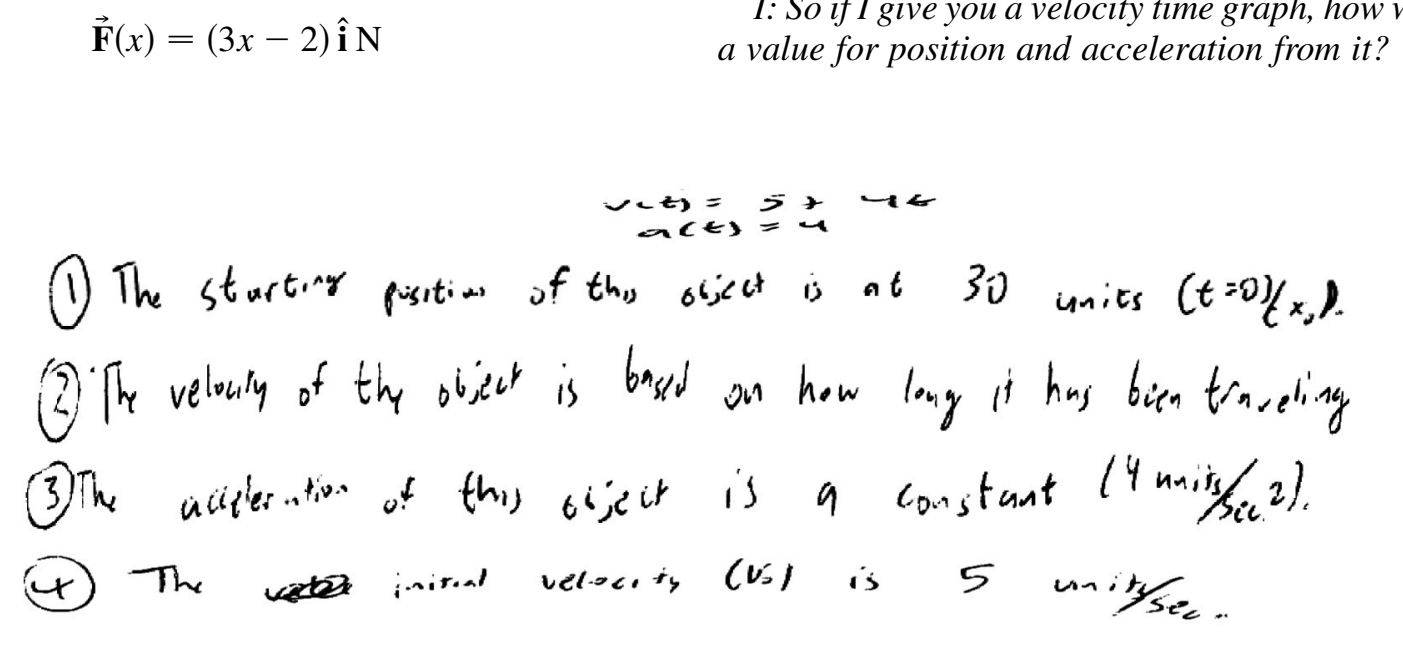

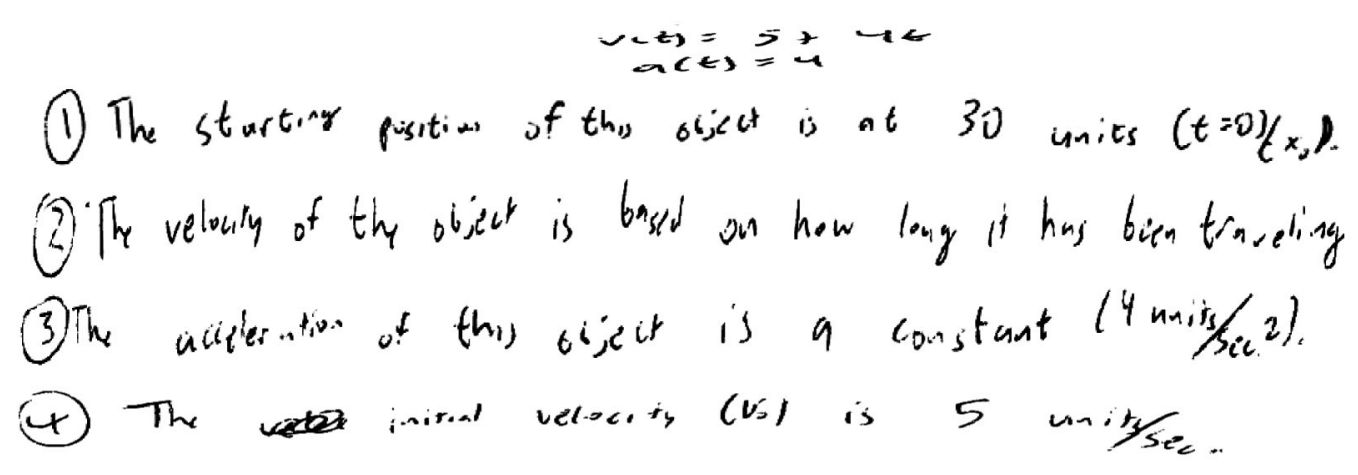

Determine the work done in moving the box to a distance of $5 \mathrm{~m}$ if its initial position was $1 \mathrm{~m}$.

Question 9: Work-Quantitative-Linguistic

A $10 \mathrm{~kg}$ box is moved along a rough horizontal surface over a distance of $15 \mathrm{~m}$ by a $20 \mathrm{~N}$ force applied at an angle of $30^{\circ}$ to the horizontal. The coefficient of kinetic friction between the box and the rough surface is 0.25 . Determine the total work done on the box.

\section{Question 10: Work-Quantitative-Graphical}

The relationship between the pressure and volume of a gas is shown in Fig. 4.

Determine the work done by the gas when the volume is increased from $5 \times 10^{-3} \mathrm{~m}^{3}$ to $15 \times 10^{-3} \mathrm{~m}^{3}$.

\section{APPENDIX B}

Examples of written solutions and interview responses for the profiles presented in Table III:

Question 1: Interpretation of position equation (See Fig. 5.)

$S$ : The initial velocity is $5 \mathrm{~m} \mathrm{~s}^{-1}$, the velocity of the object is based on how long it has been travelling and it is increasing as a function of time.

Question 4: Interpretation of acceleration-time graph (See Fig. 6.)

S: Up until the first interval of time, the velocity is constant but the velocity is not necessarily zero which means it is not accelerating. What I mean by deceleration is that the acceleration is in the opposite, the negative direction and the velocity decreases.

Question 3: Quantitative solution from velocity equation. No recognition of qualitative strategy

I: Are there any other strategies you can think of to solve this problem?

S: No...I don't have any other method to solve it.

I: So if I give you a velocity time graph, how will you find

FIG. 5. Example of qualitative solution when interpreting kinematic equation. 
S: I will try to create a velocity equation, $v(f)=v_{0}$ plus a t, that's my equation. I would solve for acceleration and then integrate to get my position.

I: You would basically use kinematics equations then...Did you not recognize that you can find the slope to get the acceleration and find the area under the graph to get the position?

S: No...I didn't think about finding the slope and area.

Question 5: Quantitative solution from motion graphs for position and velocity. Use of quantitative approach and no recognition of qualitative strategy (See Fig. 7.)

Question 2: Quantitative solution from linguistic representation. Manipulation of equations only

$S$ : Write down all that I know. Then I look at the equations I have, decides what fits. I have what I need and then I solve for it.

I: Is this how you usually solve problems, I notice you didn't include a sketch, a diagram...
S: This is because how I was taught. I guess I don't draw pictures ever. I don't really like drawing sketches. I prefer to do math with numbers. It's like I just need to pull equations out of my mind and I know how to use the equations.

Question 5: Quantitative solution from motion graphs for position and velocity. Use of both qualitative and quantitative approach (See Fig. 8.)

I: Did you realize that you can use the area under the velocity-time graph?

$S:$ No, it didn't occur to me.

I: Tell me more about it.

S: I guess for me it's a lot easier to work with these equations. I am familiar with them whereas I'm not necessarily familiar working with graphs. I can interpret what's going on in a graph [....] it's just I'm not very comfortable with that. I am more familiar with acceleration being a slope. What was more familiar is, oh this is the slope-that must be acceleration. I don't like working with areas and stuff like that. I prefer to use equations.

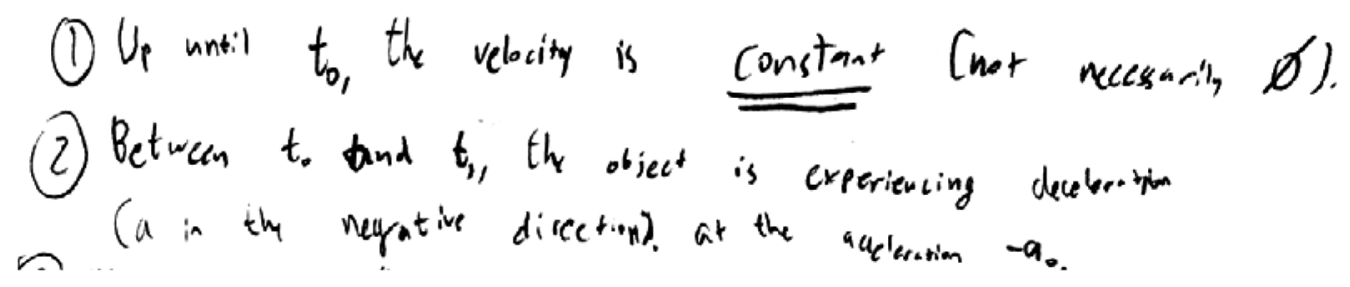

FIG. 6. Example of qualitative solution when interpreting the acceleration-time graph.

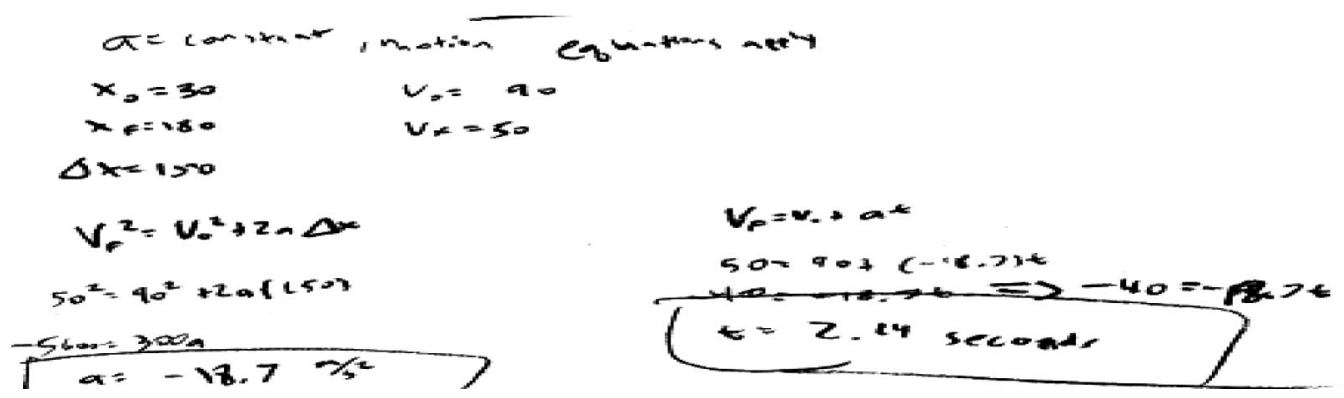

FIG. 7. Use of equations only to solve for quantitative solutions from motion graphs.

$$
\begin{aligned}
& \vec{a}=\frac{50-90}{t_{0}-0}=-\frac{40}{t_{0}} \quad x(t)=30 \mathrm{~m}+90 \mathrm{~m} / \mathrm{s} t-(1 / 2)\left(\frac{-40}{t_{0}}\right) t^{2} \\
& v_{f}^{2}-v_{i}^{2}=2 a(\Delta x) \quad a=-18(2 / 3) \\
& 50^{2}(x)-9005=2 a(180-30) \quad \frac{-40}{-18(\%)}=t_{0} \\
& -5600 \mathrm{~m}^{2} / \mathrm{s}^{2}=300 \mathrm{~m} \cdot \mathrm{a} \\
& -18\left(\frac{2}{5}\right)^{m} \%=a \\
& 2.14 \approx \epsilon
\end{aligned}
$$

FIG. 8. Use of "qualitative" approach and equations to solve for quantitative solutions from motion graphs. 


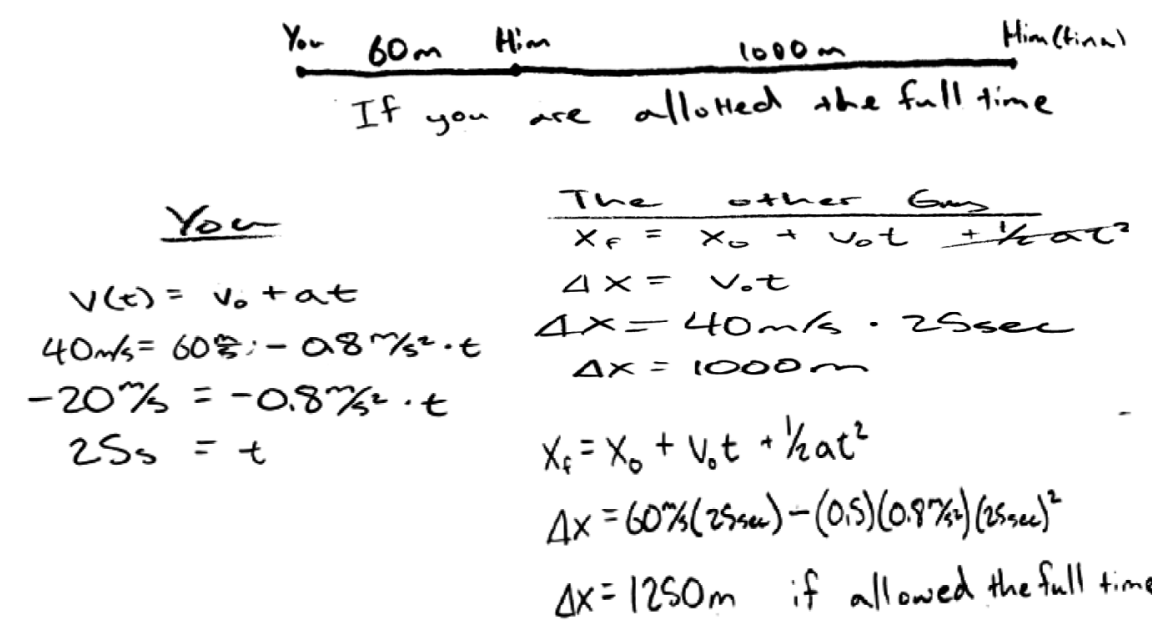

FIG. 9. Inclusion of a diagram which was ignored when dealing with equations.

Question 2: Quantitative solution from linguistic representation. Inclusion of diagram and handling of mathematical part of the problem independently of the diagram (See Fig. 9.)

I: What is the purpose of the sketch in your solution?

S: This was drawn here to kind of help me understand what was going on. I was thinking about the problem. That kind of helped me string out everything that was going on in the problem so I knew where I was shooting.

\section{APPENDIX C}

Examples of written solutions and interview responses for the profiles presented in Table VI:

Question 6: Interpretation of force-position equation (See Fig. 10.)

Question 7: Interpretation of force-position graph (See Fig. 11.)
Question 8: Quantitative solution from force-position equation. No recognition of qualitative strategy

I: What leads you to use this method?

S: The question is asking for work, we are given an equation for force and work is force times distance and I feel it is easiest to solve it in this way.

I: Do you have any other ways for solving the problem?

S: No...I don't know.

I: And did you recognize that you can actually graph it? Draw the graph of the force versus the distance?

$S$ : I didn't think about that...

Question 10: Quantitative solution from pressurevolume graph. Use qualitative strategy in a mechanical way

S: I don't know, I don't remember the equation.

I: So you take the area. What leads you to take the area?

$S$ : It's just a guess. .I have no idea...I am given a graph and that's the only thing to do with the graph.

$$
\begin{aligned}
& x \text { represents the distance trakeled by the box, } \\
& \text { and the furction } \vec{F}(x) \text { prevides the nenton force } \\
& \text { requined to mone the } 3 \mathrm{~kg} \text { box that far. The equation } \\
& \text { is aks folloned by an " } \vec{i} \text { meanima the force is } \\
& \text { only working along the } x \text {-axis. }
\end{aligned}
$$

FIG. 10. Example of description when interpreting the force-position equation.

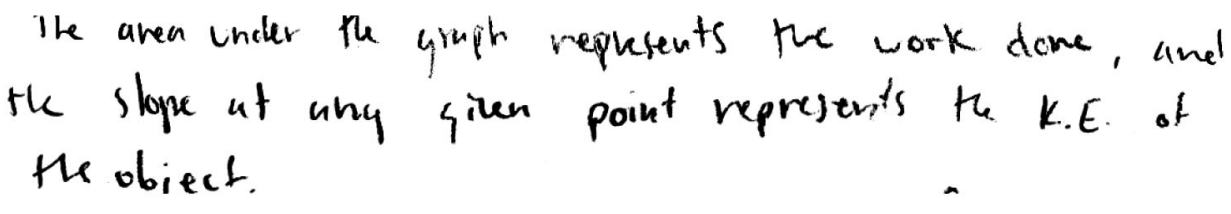

FIG. 11. Example of explanation when interpreting the force-position graph. 


$$
N=F \cdot d=\int F d x=\int_{1}^{5}(3 x-2) d x=\left.\left(\frac{3}{2} x^{2}-2 x\right)\right|_{1} ^{5}=27.5+0.5=28 J
$$

FIG. 12. Use of quantitative approach to solve for a quantitative solution from force-position equation.

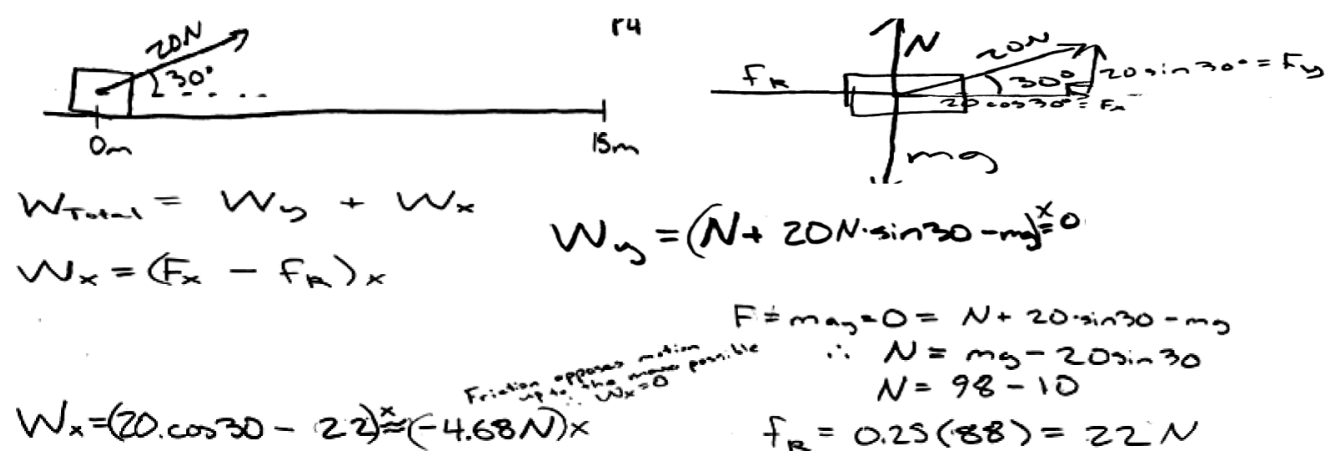

FIG. 13. Inclusion of diagrams which were used in conjunction with equations.

\section{Question 9: Quantitative solution from linguistic representation}

I: What was the purpose of the sketch here and the force diagram?

S: Just to know what I am doing and what I have so that I can figure out where to go.

I: How does it help you?

S: Helps me visualize it so I can really make sense of what's going on.

I: Did you use it with the mathematical part? Did it help you with the mathematical part?

S: Not really....I guess a little bit to make sure I write the right stuff down.

Question 8: Quantitative solution from force-position equation. Uses quantitative approach although recognizes qualitative strategy (See Fig. 12.)

S: Work is force times distance and so like if you have a graph or something, if you take the area it will give you force times distance as well.

I: Ok, do you have any other ways which you can solve the problem?
S: I could have drawn $3 x$ minus 2 , a graph and take the area underneath it.

I: What prompts you to take the integral here?

$S$ : It is faster and much simpler to use integral than drawing the graph and then find the area.

Question 9: Quantitative solution from linguistic representation. Includes diagram used when handling the mathematical part of the problem (See Fig. 13.)

$S:$ I started by drawing this diagram here [....] I drew a force diagram, force due to friction which oppose motion, the normal force, the force of gravity and I find the components. I said the total work done would be work done in the $y$ direction plus work done in the $x$ direction.

I: $O k$, did these visual representations help you with the mathematical part?

S: Yes. They help me to visualize it. I knew what was going on to put to the components. . it's better drawing the force with the angle, it gives you a better idea so that way you can't confuse sine and cosine.
[1] P. Heller, R. Keith, and S. Anderson, Teaching problem solving through cooperative grouping. Part 1: Group versus individual problem solving, Am. J. Phys. 60, 627 (1992).

[2] L. C. McDermott, P.S. Shaffer, and M. D. Somers, Research as a guide for teaching introductory mechanics: An illustration in the context of the Atwood's machine, Am. J. Phys. 62, 46 (1994).
[3] P.W. Laws, Calculus-based physics without lectures, Phys. Today 44, No. 12, 24 (1991).

[4] J. M. Wilson, The CUPLE physics studio, Phys. Teach. 32, 518 (1994).

[5] W. J. Leonard, R. J. Dufresne, and J.P. Mestre, Using qualitative problem-solving strategies to highlight the role of conceptual knowledge in solving problems, Am. J. Phys. 64, 1495 (1996). 
[6] R. J. Beichner, J. M. Saul, D. S. Abbott, J. J. Morse, D. L. Deardorff, R. J. Allain, S. W. Bonham, M. H. Dancy, and J.S. Risley, The Student-Centered Activities for Large Enrollment Undergraduate Programs (SCALE-UP) project, in Research-Based Reform of University Physics, edited by E.F. Redish and P.J. Coonet (American Association of Physics Teachers, College Park, MD, 2007), Reviews in PER Vol. 1, http://www .percentral.com/PER/per_reviews/media/volume1/SCALEUP-2007.pdf.

[7] G. Polya, How to Solve It (Princeton University Press, Princeton, NJ, 1957).

[8] J.D. Bransford and B.S. Stein, The IDEAL Problem Solver (W. H. Freeman, New York, 1984).

[9] D. H. Jonassen, Learning to Solve Problems: A Handbook for Designing Problem-Solving Learning Environments (Routledge, New York, 2011).

[10] D. E. Meltzer, Relation between students' problemsolving performance and representational format, Am. J. Phys. 73, 463 (2005).

[11] R. R. Cadmus, Jr., A video technique to facilitate the visualization of physical phenomena, Am. J. Phys. 58, 397 (1990).

[12] L. T. Escalada and D. A. Zollman, An investigation on the effects of using interactive digital video in a physics classroom on student learning and attitudes, J. Res. Sci. Teach. 34, 467 (1997).

[13] S. Ainsworth, The functions of multiple representations, Comput. Educ. 33, 131 (1999).

[14] R. Cox, Representation construction, externalised cognition and individual differences, Learn. Instr. 9, 343 (1999).

[15] S. R. Goldman, Learning in complex domains: When and why do multiple representations help?, Learn. Instr. 13, 239 (2003).

[16] D. N. Rapp, in Visualization in Science Education, edited by J. K. Gilbert (Springer, Dordrecht, 2007).

[17] E. Etkina, A. Van Heuvelen, S. White-Brahmia, D. T. Brookes, M. Gentile, S. Murthy, D. Rosengrant, and A. Warren, Scientific abilities and their assessment, Phys. Rev. ST Phys. Educ. Res. 2, 020103 (2006).

[18] L. C. McDermott and P. S. Shaffer, Research as a guide for curriculum development: An example from introductory electricity. Part I: Investigation of student understanding, Am. J. Phys. 60, 994 (1992).

[19] R. J. Beichner, Testing student interpretation of kinematics graphs, Am. J. Phys. 62, 750 (1994).

[20] P. Colin, F. Chauvet, and L. Viennot, Reading images in optics: Students' difficulties and teachers' views, Int. J. Sci. Educ. 24, 313 (2002).

[21] A. Van Heuvelen, Overview, Case Study Physics, Am. J. Phys. 59, 898 (1991).

[22] R. J. Dufresne, W. J. Gerace, and W. J. Leonard, Solving physics problems with multiple representations, Phys. Teach. 35, 270 (1997).

[23] D. Rosengrant, A. Van Heuvelen, and E. Etkina, Freebody diagrams: Necessary or sufficient?, AIP Conf. Proc. 790, 177 (2005).

[24] C. DeLeone and E. Gire, Is instructional emphasis on the use of non-mathematical representation worth the effort? in Proceedings of Physics Education Research
Conference, Salt Lake City, UT, 2006, edited by $\mathrm{P}$. Heron, L. McCullough, and J. Marx (AIP, Melville, NY, 2005).

[25] P. B. Kohl, D. Rosengrant, and N. D. Finkelstein, Strongly and weakly directed approaches to teaching multiple representation use in physics, Phys. Rev. ST Phys. Educ. Res. 3, 010108 (2007).

[26] A. Van Heuvelen and D. P. Maloney, Playing Physics Jeopardy, Am. J. Phys. 67, 252 (1999).

[27] T. Seufert, Supporting coherence formation in learning from multiple representations, Learn. Instr. 13, 227 (2003).

[28] D. Bodemer, R. Ploetzner, K. Bruchmüller, and S. Häcker, Supporting learning with interactive multimedia through active integration of representations, Instr. Sci. 33, 73 (2005).

[29] B.E. Hinrichs, Using the system schema representational tool to promote student understanding of Newton's third law, AIP Conf. Proc. 790, 117 (2005).

[30] R.E. Mayer and R.B. Anderson, The instructive animation: Helping students build connections between words and pictures in multimedia learning, J. Educ. Psychol. 84, 444 (1992).

[31] S. Ainsworth, P. Bibby, and D. Wood, Examining the effects of different multiple representational systems in learning primary mathematics, J. Learn. Sci. 11, 25 (2002).

[32] R.E. Mayer, The promise of multimedia learning: Using the same instructional design methods across different media, Learn. Instr. 13, 125 (2003).

[33] T. Stelzer, G. Gladding, J. P. Mestre, and D. T. Brookes, Comparing the efficacy of multimedia modules with traditional textbooks for learning introductory physics content, Am. J. Phys. 77, 184 (2009).

[34] P. B. Kohl and N. D. Finkelstein, Student representational competence and self-assessment when solving physics problems, Phys. Rev. ST Phys. Educ. Res. 1, 010104 (2005).

[35] P. B. Kohl and N. D. Finkelstein, Effect of representation on students solving physics problems: A fine-grained characterization, Phys. Rev. ST Phys. Educ. Res. 2, 010106 (2006).

[36] R.E. Mayer, Different problem-solving strategies for algebra word and equation problems, J. Exp. Psychol. Learn. Mem. Cogn. 8, 448 (1982).

[37] K. R. Koedinger and M. J. Nathan, The real story behind story problems: Effects of representations on quantitative reasoning, J. Learn. Sci. 13, 129 (2004).

[38] E. Mazur, Peer Instruction: A User's Manual (PrenticeHall, Upper Saddle River, NJ, 1996).

[39] M. S. Sabella, Ph.D. thesis, University of Maryland, 1999.

[40] L. N. Walsh, R.G. Howard, and B. Bowe, Phenomenographic study of students' problem solving approaches in physics, Phys. Rev. ST Phys. Educ. Res. 3, 020108 (2007).

[41] B. Ibrahim, A. Buffler, and F. Lubben, Profiles of freshman physics students' views of the nature of science, J. Res. Sci. Teach. 46, 248 (2009).

[42] M. T. H. Chi, P. J. Feltovich, and R. Glaser, Categorization and representation of physics problems by experts and novices, Cogn. Sci. 5, 121 (1981). 
[43] R. B. Kozma and J. Russell, Multimedia and understanding: Expert and novice responses to different representations of chemical phenomena, J. Res. Sci. Teach. 34, 949 (1997).

[44] P. B. Kohl and N.D. Finkelstein, Patterns of multiple representation use by experts and novices during physics problem solving, Phys. Rev. ST Phys. Educ. Res. 4, 010111 (2008).

[45] P. Johnson-Laird, Mental Models (Harvard University Press, Cambridge, 1983).
[46] S. Ainsworth, DeFT: A conceptual framework for considering learning with multiple representations, Learn. Instr. 16, 183 (2006).

[47] J. D. Gobert, in Visualization in Science Education, edited by J. K. Gilbert (Springer, Dordrecht, 2007).

[48] I. M. Greca and M.A. Moreira, The kinds of mental representations-models, propositions and images-used by college physics students regarding the concept of field, Int. J. Sci. Educ. 19, 711 (1997). 